\title{
Determinants of plasma lipoproteins and coagulation factors in men from Caerphilly, South Wales
}

\author{
J W G YARNELL, ${ }^{1}$ ANN M FEHILY, ${ }^{1}$ JANET MILBANK, ${ }^{*}$ A J KUBICKI, ${ }^{1} \dagger$ \\ R EASTHAM, ${ }^{4}$ AND T M HAYES ${ }^{3}$ \\ From the MRC Epidemiology Unit, ${ }^{1}$ Cardiff, Frenchay Hospital, ${ }^{2}$ Bristol, and the Department of Medicine, ${ }^{3}$ \\ University Hospital of Wales, Cardiff, UK
}

SUMmARY Dietary, social, and constitutional determinants of plasma concentrations of some major risk factors for ischaemic heart disease were investigated in a cross sectional study among 711 men from the general population aged 30-69. For high density lipoprotein cholesterol (HDL-C) six variables were significantly associated with plasma concentrations, and these variables explained $12.6 \%$ of the variance. For low density lipoprotein cholesterol (LDL-C), total cholesterol (T-C), and triglyceride $8 \cdot 4 \%, 7 \cdot 5 \%$, and $18 \cdot 5 \%$ of the variance was explained by significantly associated variables. Fibrinogen concentrations determined chemically were significantly associated with age, smoking habit, body mass index, alcohol consumption, and intake of cereal fibre $(24.2 \%$ variance). These data provide some encouragement for the possibility of dietary intervention to influence plasma concentrations of major risk factors for ischaemic heart disease in men.

High density lipoprotein cholesterol (HDL-C) has been rediscovered recently to be an important risk factor for ischaemic heart disease (IHD). ${ }^{1-3}$ Interest has focused also on coagulation factors ${ }^{4}$ in the aetiology of IHD. Little is known about the major determinants of these factors in plasma; the purpose of the present paper is to examine these in a prevalence study among a random sample of 711 men aged 30-69. Similar data for over 2000 men aged 45-59 will be available shortly.

\section{Methods}

\section{STUDY POPULATION}

A random sample of men was drawn from the electoral registers for the town of Caerphilly and two outlying villages (population 38000 ) in South Wales. All men were sent an initial letter but were only considered eligible for inclusion in the study if aged 30-69; a total of 797 men came into this category and were invited to attend a local clinic.

\section{SURVEY METHODS}

Details of the medical history, physical measurements, and nutritional questionnaire ${ }^{5}$ have been described in detail previously ${ }^{6}$ in a similar study among women.

\section{LABORATORY MEASUREMENTS}

A venous blood sample was taken with minimum stasis after an overnight fast (minimum eight hours, average 12 hours). HDL-C was estimated in supernatant by enzymatic assay ${ }^{7}$ after precipitation of the remaining lipoprotein fractions, usually within six hours by the use of sodium heparin/ $\mathrm{Mn} \mathrm{Cl}_{2}$ $(46 \mathrm{mM}) .^{8}$ Total cholesterol (T-C) was estimated on EDTA plasma by the same enzymatic assay? (Boehringer). Low density lipoprotein cholesterol (LDL-C) was calculated from the formula of Friedewald et al ${ }^{9}$

$$
\left(\mathrm{LDL}-\mathrm{C}=\mathrm{T}-\mathrm{C}-\left[\mathrm{HDL}-\mathrm{C}-\frac{(\mathrm{TG} \times 18)}{38 \cdot 7}\right]\right.
$$

(mmols). Triglycerides were estimated by enzymatic assay. ${ }^{10}$ Fibrinogen was estimated by two methods; a chemical method ${ }^{11}$ on EDTA plasma and a clotting assay ${ }^{12}$ on citrated plasma. Viscosity was estimated on EDTA plasma by the method of Thorp et al ${ }^{13}$ and haematocrit by a standard capillary tube

- Present address: John Radcliffe Hospital, Oxford.

† Present address: Department of Clinical Investigation, Diabetic Department, Dudley Road Hospital, Birmingham. 
method. Factor VII assay ${ }^{14}$ was carried out on citrated plasma using plasma derived from beagles. For convenience, clotting fibrinogen (fibrinogen clotting time) has been converted to similar units to those obtained biochemically; but in the case of factor VII assays a shorter clotting time indicates a higher level of factor VII activity.

Quality control was maintained during the course of the study by the use of pooled plasma standards where appropriate, duplicate samples presented "blindly" to the laboratory and second samples taken from a small group of men some four to 12 weeks after the first sample. In the case of the "split" samples the coefficients of variation for T-C, HDL-C, triglycerides, fibrinogen (chemical), fibrinogen (clotting), viscosity, and factor VII were $4.0 \%$, $13.3 \%, 4 \cdot 8 \%, 5 \cdot 3 \%, 10 \cdot 0 \%, 2 \cdot 3 \%$, and $3 \cdot 1 \%$ respectively. For the second samples the coefficients of variation were $6.9 \%, 18.1 \% *, 22.6 \%{ }^{*} 10.3 \%$, $17 \cdot 9 \%, 2 \cdot 4 \%$, and $4 \cdot 1 \%$.

\section{STATISTICAL METHODS}

Univariate analyses were done initially to determine which variables were entered into a multiple linear regression by a stepwise (forward inclusion) procedure. The dependent variable that explained the greatest proportion of the variance in the independent variable was entered initially; the variable that explained the greatest percentage of the remaining variance was entered next; and so on, so that each additional variable yielded the maximum increase in the proportion of the total variance explained.

\section{Results}

Of 797 men eligible for inclusion in the study, 711 $(89 \%)$ were examined and $700(88 \%)$ provided a blood sample. Dietary questionnaires were returned by $697 \mathrm{men}(87 \%)$. Because of missing information it was not possible to obtain complete regression analyses on all members of the study sample: however, non-respondents had a similar level of morbidity to those subjects with complete information..

Table 1 lists the variables that remained significantly associated with the lipid variables after completion of the regression analyses on 670 men with complete information. LDL-C and triglyceride values were transformed because their distributions were skewed; similar variables were associated with the untransformed data.

In the case of HDL-C a total of $12.6 \%$ of the variance was explained by the significantly associated variables. An additional $1.0 \%$ of the variance was
Table 1 Accumulative percentage of variance in plasma concentrations of lipids in 670 men, which is explained by age, smoking habit, etc

\begin{tabular}{|c|c|c|}
\hline & $\begin{array}{l}\text { Accumulative percentage } \\
\text { of variance explained }\end{array}$ & $\begin{array}{l}\text { Directionof } \\
\text { association }\end{array}$ \\
\hline \multicolumn{3}{|l|}{ HDL-Cholesterol: } \\
\hline \multicolumn{3}{|c|}{ per cent } \\
\hline Body mass index (Quetelet's) & $5 \cdot 8$ & - \\
\hline Smoking habit & 8.7 & - \\
\hline Alcohol & $10 \cdot 1$ & + \\
\hline Age & $11 \cdot 2$ & + \\
\hline Longevity & $12 \cdot 0$ & + \\
\hline Vitamin C & $12 \cdot 6$ & + \\
\hline \multicolumn{3}{|l|}{ LDL-Cholesterol:* } \\
\hline Age & $2 \cdot 1$ & + \\
\hline Milk & $3 \cdot 7$ & + \\
\hline Animal protein & $5 \cdot 7$ & - \\
\hline Longevity & $7 \cdot 2$ & - \\
\hline Smoking habit & $8 \cdot 4$ & + \\
\hline \multicolumn{3}{|l|}{ Total cholesterol: } \\
\hline Age & $3 \cdot 3$ & + \\
\hline Longevity & 6.4 & - \\
\hline Milk & $7 \cdot 5$ & + \\
\hline \multicolumn{3}{|l|}{ Triglyceride:* } \\
\hline Body mass index & $10 \cdot 7$ & + \\
\hline Alcohol & $14 \cdot 3$ & + \\
\hline Smoking habit & $16 \cdot 0$ & + \\
\hline Starch (\%calories) & $16 \cdot 8$ & + \\
\hline Age & $17 \cdot 7$ & + \\
\hline Cereal fibre & $18 \cdot 5$ & - \\
\hline
\end{tabular}

"Values transformed to logarithms.

explained by including four more non-significantly associated variables. For LDL-C $8.4 \%$ of the variance was explained by significantly associated variables-age, milk consumption, animal protein, longevity, and smoking habit. T-C had only $7 \cdot 5 \%$ of its variance explained by significantly associated variables; an additional $0.5 \%$ of the variance was explained by including an additional non-significantly associated variable (Quetelet's index). A total of $18.5 \%$ of the variance in plasma concentrations of triglyceride was explained by significantly associated variables.

Table 2 shows the accumulative percentage of the variance explained by variables significantly associated with plasma concentrations of certain coagulation factors in 658 men with complete results. Chemical fibrinogen was associated principally with age and smoking habit but body mass index, alcohol consumption, and cereal fibre contributed a further $2.9 \%$ of the variance. Clotting fibrinogen was significantly associated only with age and smoking habit. Viscosity was similarly associated principally with age, body mass index, and smoking habit. Factor VII levels were significantly, and only weakly, associated with age; but an additional $2 \cdot 3 \%$ of the variance was explained by including four non-significantly associated variables. 
Table 2 Accumulative percentage of the variance in plasma concentrations of coagulation factors in 658 men, which is explained by age, smoking habit, etc

\begin{tabular}{|c|c|c|}
\hline & $\begin{array}{l}\text { Accumulative percentage } \\
\text { of variance explained }\end{array}$ & $\begin{array}{l}\text { Directionof } \\
\text { association }\end{array}$ \\
\hline \multicolumn{3}{|l|}{ Fibrinogen, chemical:* } \\
\hline \multicolumn{3}{|c|}{ per cent } \\
\hline Age & $12 \cdot 8$ & + \\
\hline Smoking habit & $21 \cdot 3$ & + \\
\hline Body mass index & $22 \cdot 8$ & + \\
\hline Alcohol & $23 \cdot 5$ & - \\
\hline Cereal fibre & $24 \cdot 2$ & - \\
\hline \multicolumn{3}{|l|}{ Fibrinogen, clotting:* } \\
\hline Age & $10 \cdot 2$ & + \\
\hline Smoking habit & $15 \cdot 4$ & + \\
\hline \multicolumn{3}{|l|}{ Viscosity:* } \\
\hline Age & $5 \cdot 7$ & + \\
\hline Body mass index (Quetelet's) & $7 \cdot 5$ & + \\
\hline Smoking habit & $9 \cdot 3$ & + \\
\hline Vegetable oil & $10 \cdot 4$ & - \\
\hline \multicolumn{3}{|l|}{ Factor VII:* } \\
\hline Age & 0.9 & - \\
\hline
\end{tabular}

*Values transformed to logarithms.

\section{Discussion}

This study shows that dietary factors can be associated with major plasma lipid components within the same population. In the case of HDL-C, however, some caution should be exercised in the interpretation of the results since different dietary factors have been reported by members of our group to be associated with plasma HDL-C in women ${ }^{6}$ and in a further sample of 117 men $^{15}$ aged 44-60. In the present study a further plasma sample was assayed for lipoproteins in a separate laboratory ( $\mathrm{Dr} \mathrm{C}$ Bolton, Bristol) and slightly different results were obtained for HDL-C in which $5 \cdot 3 \%$ of the variance is explained by four variables; alcohol $(+v e)$, smoking habit (-ve), vegetable fibre (+ve), and age (+ve). A common finding, however, in this population is a slight increase in HDL-C with age.

LDL-C, T-C, and triglycerides show a larger degree of consistency in results obtained from the two laboratories. LDL-C (which was calculated by means of a direct result from VLDL-C and HDL-C in the case of the Bristol laboratory) is consistently associated with age, milk consumption, longevity, and smoking habit. T-C is consistently associated with age, longevity, and milk consumption. Triglycerides had a high percentage of the variance explained by similar factors for results from both laboratories (18.5 and $20.3 \%$ respectively). Consistent associations, all of which were positive, were shown for body mass index, alcohol consumption, smoking habit, and age. Although internal consistency within the data provides a certain measure of reassurance, these data are based on multiple comparisons of relatively small numbers of subjects. Analysis of larger samples should provide more secure data.

Chemical and clotting fibrinogen levels have been reported to be associated with prevalent IHD ${ }^{16}$ and clotting fibrinogen with incident IHD. ${ }^{4}$ In the present study chemical and clotting methods were done independently in separate laboratories. Chemical fibrinogen was associated with age and cereal fibre intake in a further sample of 117 men $^{15}$ aged 44-60 for whom detailed seven day weighted dietary records were available. In these present data consistent associations were noted between fibrinogen concentrations and age, smoking habit, body mass index, alcohol consumption, and intake of cereal fibre although in the case of clotting fibrinogen only age and smoking habit were statistically significant. Similar findings have been noted in another cross sectional study, ${ }^{17}$ but in this study dietary factors other than alcohol consumption were not apparently investigated. The mechanism by which an acute phase reactant such as fibrinogen ${ }^{18}$ can be influenced by intake of cereal fibre currently remains obscure, but the association would seem to warrant testing by means of an intervention study.

In these data chemical fibrinogen concentrations and plasma viscosity are highly correlated $(r=0 \cdot 60)$. In a multiple logistic regression analysis ${ }^{19}$ viscosity was not independently associated with prevalent IHD, its apparent univariate association being entirely explained by fibrinogen.

Although certain of these data such as the dietary determinants of HDL-C must be regarded as provisional because of inconsistent results, they provide some encouragement for the possibility of dietary interventions to reduce levels of the major plasma risk factors.

We thank Dr P C Elwood for his continuous support and encouragement and Michael Etherington from Dr O'Brien's laboratory (Portsmouth) for carrying out the clot:ing fibrinogen and factor VII assays.

\section{References}

${ }^{1}$ Gordon T, Castelli WP, Hjortland M, Kannel WB, Dawber TK. High density lipoprotein as a protective factor against coronary heart disease. The Framingham study. Am J Med 1977; 62: 707-14.

${ }^{2}$ Miller NE, Forde OH, Thelle DS, Mjos OD. The Tromso heart study. High density lipoprotein and coronary heart disease: a prospective case-control study. Lancet 1977; i: 965-7.

${ }^{3}$ Goldbourt U, Medalie JH. High density lipoprotein cholesterol and incidence of coronary heart disease-The Israeli ischaemic heart disease study. Am J Epidemiol 1979; 109: 296-308.

${ }^{4}$ Meade TW, North WRS, Chakrabarti R, Stirling Y, Haines AP, Thompson SG, Brozovic M. Haemostatic function and cardiovascular death: early results of a prospective study, Lancet 1980 ; i: $1050-4$. 
'Yarnell JWG, Fehily AM, Milbank JE, Sweetnam PM, Walker CL. A short dietary questionnaire for use in an epidemiological survey. $J$ Hum Nutr (in press).

- Yarnell JWG, Milbank J, Walker CL, Fehily AM, Hayes TM. Determinants of HDL and total cholesterol in women. An epidemiological study from Caerphilly, South Wales. J Epidem Community Health 1982; 36: 167-71.

${ }^{7}$ Steele BW, Koehler DF, Kuba K, Azar MM. An enzymatic approach to lipoprotein quantification. Am J Clin Pathol 1980; 73: 75-8.

${ }^{8}$ Albers JJ, Warnick GR, Johnson N, et al. Quality control of plasma high-density lipoprotein cholesterol measurement methods. Circulation 1980; 62, suppl 4: 9-17.

${ }^{9}$ Friedewald WT, Levy RI, Fredrickson DS. Estimation of LDL-cholesterol in plasma without use of the preparative ultracentrifuge. Clin Chem 1972; 18: 499-502.

${ }^{10}$ Buccolo G, David H. Quantitative determination of serum triglycerides by the use of enzymes. Clin Chem 1973; 19: 476-82.

${ }^{11}$ Thorp JM, Horsfall GB, Stone MC. A new red-sensitive micronephelometer. Medical and Biological Engineering 1967; 5: 51-6.

${ }^{12}$ Clauss A. Gerrinnungephysiologische Schnellmethode sur Bestimmung des Fibrinogens. Acta Haematol 1957; 17: $237-46$.
${ }^{13}$ Harkness J. The viscosity of human blood plasma; its measurement in health and disease. Biorheology 1971; 8: 171-93.

${ }^{14}$ Nemerson Y, Clyne LP. An assay for factor VII using factor VII-depleted bovine plasma. J Lab Clin Med 1974; 83: 301-3.

${ }^{15}$ Fehily AM, Milbank JE, Yarnell JWG, Hayes TM, Kubicki AJ, Eastham RD. Dietary determinants of lipoproteins, total cholesterol, viscosity and blood pressure. Am J Clin Nutr 1982; 36: 890-6.

${ }^{16}$ Baker IA, Eastham R, Elwood PC, Etherington M, O'Brien JR, Sweetnam PM. Haemostatic factors associated with ischaemic heart disease in men aged 45 to 64 years. Br Heart J 1982; 47: 490-4.

${ }^{17}$ Meade TW, Chakrabarti R, Haines AP, North WRS, Stirling Y. Characteristics affecting fibrinolytic activity and plasma fibrinogen concentrations. $\mathrm{Br} M e d \mathrm{~J} 1979$; i: 153-6.

${ }^{18}$ Pilgeram LO. Relation of plasma fibrinogen concentration changes to human arteriosclerosis. J Appl Physiol 1961; 16: 660-4.

${ }^{19}$ Medical Research Council Epidemiology Unit. The Caerphilly collaborative survey progress report IV. Cardiff: MRC, 1982. 